49 Who wrote about the psychotic breakdown of Nicole Diver?
50 What connects Eysenck, Asperger and Creutzfeldt with a patient of Freud and a clever horse?

\title{
Christmas Crossword
}

\author{
by Oedipus \& Witzelsucht
}

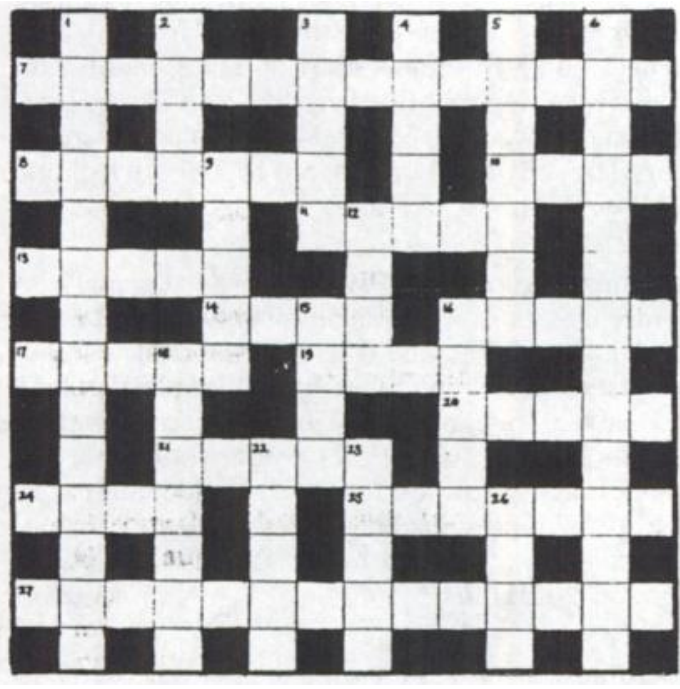

Across

7 First principle for psychiatrists, second part of couplet, third molar and female scout! $(3,6,5)$

8 One golfer plays a round and produces a double bogey. (7)

10 Transcultural syndrome from Birmingham, Oklahoma. (4)

11 Belief - often without a preposition, but with the first two units of ethyl alcohol. (5)

$13 \& 20$ R. D. Laing, for example, leads sound resistance to attempt to find his blind spot. (10)

14 Part of Sci-fi show reveals phenomenal man (or beast). (4)

16 What is detected in a frontal lobe tumour? In short, the science of ear, nose and throat. (5)

17 Sadness can be good! (exclamation). (5)

19 Unresponsive state brought on by the company of my mother. (4)

20 See 13.

21 What lithium does $-50 \%$ chance. (5)

24 Emetic brings back something from inside. (4)

25 Listen to Freud's daughter; listen to the psychotherapist. (7)

27 Bet Channel rail mix-up will lead to a psychiatrist with a taste for humanity. $(8,6)$
Prizes of the College 'Shrink Proof T-shirts will be given for the first correctly completed crossword drawn out of a hat and for the person or group (maximum four people) who answers correctly the most trivia questions, with a draw in the event of a tie. Entries for both competitions should be sent to Dr Matt Jelley and Dr John Owen, University Department of Mental Health, 41 St Michael's Hill, Bristol BS2 8DZ to arrive not later than 31 January 1992.

The names of the winners and answers to the competition will appear in the April 1992 issue of the Psychiatric Bulletin.

\section{Down}

1 At this time of year, Mr Rich becomes delirious in Ramsey St. $(5,9)$

2 The in-patient wiggles: off his tree! (4)

3 Confess transfer to hospital. (5)

4 Hippocampal Horn meets Headless Deity. (5)

5 Madman, deranged in a cult. (7)

6 "Quirks? No dice. sirs" I say, confused. (14)

9 Neurophysiological phenomenon in which one says "Oh No!" very loudly. $(2,3)$

12 Local Journal, local Journal. (4)

15 Investigation useful in psychosis (cannabisinduced). (4)

16 South American doctor leads us a merry dance. (5)

22 Lancashire town in which Eysenck and Rorschach battled (Yorkshire, initially). (5)

23 Drug rep's purpose on a boat? (5)

26 Coereleus etc. see one go up a mountain pass. (4) 